\title{
RESEARCH
}

Open Access

\section{Optimal use of antiplatelet agents, especially aspirin, in the perioperative management of colorectal cancer patients undergoing laparoscopic colorectal resection}

Yasunori Yoshimoto*, Takahisa Fujikawa, Akira Tanaka, Hideto Hayashi, Norihiro Shimoike, Hiroshi Kawamoto, Chiyo Nakasuga and Tsunenori Yamamoto

\begin{abstract}
Background: Laparoscopic abdominal surgery is considered superior to open surgery. However, efficacy and safety outcomes of laparoscopic surgery in colorectal cancer (CRC) are unclear, particularly in patients undergoing antiplatelet therapy (APT). The aim of this study was to evaluate safety of antiplatelet agents, especially aspirin, in peri-operative management of patients undergoing laparoscopic colorectal resection for CRC.

Methods: A total of 578 radical laparoscopic colorectal surgeries in CRC patients performed between January 2005 and December 2015 at the Kokura Memorial Hospital were retrospectively reviewed. Patients were divided into three groups based on the risk for thromboembolism: a high-risk group receiving APT (APT-HR), a low-risk group receiving APT (APT-LR), and a low-risk group not receiving APT (non-APT). Bleeding complications (BC) and thromboembolic complications (TC) were assessed. Perioperative and outcome variables in groups receiving APT were compared with those in the non-APT group.

Results: APT-HR, APT-LR, and non-APT groups included 54 (9.3\%), 114 (19.7\%), and 410 (70.9\%) patients, respectively. Blood loss during operation $(p=0.304)$, operative time $(p=0.956)$, hospitalisation after surgery $(p=$ 0.307), and Clavien-Dindo classification of surgery-related complications ( $p=0.467)$ were not significantly different in the three groups. Occurrence of intra-operative BC (blood loss $\geq 200 \mathrm{ml})(p=0.864)$, post-operative BC ( $p=$ $0.630)$, and TC ( $p=0.287)$ were also not significantly different in the three groups. Results of our analysis indicated that APT and non-interrupted APT were not associated with BC or TC.
\end{abstract}

Conclusions: Analysis of laparoscopic colorectal resection in CRC showed that APT was not a major factor for fatal $\mathrm{BC}$ or TC. In patients with high thromboembolic risk, continuing aspirin may inhibit the increase in TC without increasing $B C$ in the peri-operative period.

Keywords: Antiplatelet therapy, Colorectal cancer, Laparoscopic surgery, Bleeding complications, Thromboembolic complications

\footnotetext{
* Correspondence: yyasu@wg8.so-net.ne.jp

Department of Surgery, Kokura Memorial Hospital, 3-2-1, Asano, Kokura-kita,

Kitakyushu, Fukuoka 802-8555, Japan
}

(c) The Author(s). 2019 Open Access This article is distributed under the terms of the Creative Commons Attribution 4.0 International License (http://creativecommons.org/licenses/by/4.0/), which permits unrestricted use, distribution, and 


\section{Introduction}

The recent developments in science and technology have improved the life span and quality of life of the ageing population with disorders. Antiplatelet and anticoagulant agents are used to prevent cardiovascular events in those with cardiovascular complications. The use of perioperative antithrombotic therapy (ATT) for primary and secondary prevention of cardiovascular and/or cerebrovascular complications during abdominal surgery significantly affects the incidence of intra- and postoperative bleeding complications (BC) or thromboembolic complications (TC). In particular, discontinuing antiplatelet therapy (APT) during the perioperative period increases the risk of TC. Moreover, intra- or postoperative $\mathrm{BC}$ may occur more often when $\mathrm{APT}$ is continued before or during surgery.

Laparoscopic surgery is an established procedure and a standard operative approach in many general surgeries. Although laparoscopic abdominal surgery has been suggested to be superior to conventional open surgery, the efficacy and safety outcomes of laparoscopic surgery for colorectal cancer are still unclear. In particular, the safety of laparoscopic abdominal surgery in patients taking antiplatelet drugs for cardiovascular disorders is not guaranteed. No study has examined the safety of perioperative APT in laparoscopic colorectal resection for colorectal cancer.

This study aimed to review and evaluate the surgical outcomes, particularly perioperative $\mathrm{BC}$ and $\mathrm{TC}$ under APT, of colorectal cancer patients undergoing laparoscopic colorectal resection.

\section{Materials and methods}

Between January 2005 and December 2015, 5202 abdominal gastroenterological surgical procedures were performed at our institution. Among them, 578 radical laparoscopic colorectal surgeries were performed for colorectal cancer patients, and these cases were retrospectively reviewed in this study. Patients who met the following inclusion criteria were included: histologically diagnosed colorectal cancer, tumour located in the caecum-rectum $(\mathrm{Rb}), \mathrm{T} 1-\mathrm{T} 3$ or $\mathrm{T} 4$ without involvement to other organs, N0-3 node stage, and M0 metastasis stage. Cases of emergency surgery, laparoscopic surgery later converted to open surgery, and those with insufficient information in the medical records were excluded.

The patients were divided into three groups according to the risk for theromboembolism. Obesity, smoking, old age, history of thromboembolic disease and predisposition, in particular, based on the presence or absence of ATT for heart disease and cerebrovascular disease were the risk factors. Since we focused on APT this time, so we handled anticoagulant therapy (ACT) as described later. Preoperative use of ATT (APT and/or ACT) was as shown in Fig. 1. APT was performed in 168 cases (29.1\%) out of 578 cases. The antiplatelet agent is considered to be at high risk for thromboembolism with discontinuation, and the patient with antiplatelet agent was judged to be at risk. We defined the group with both low risk of thromboembolism and without an antiplatelet agent as the non-APT group $(n=$ 410). Patients with the following characteristics were considered to have high thromboembolic risks: (1) undergoing drug-eluting coronary stent (DES) implantation regardless of the interval between DES implantation and surgical procedures, (2) underwent drug-noneluting coronary baremetal stent implantation within 2 months, (3) undergoing cerebrovascular reconstruction within 2 months, (4) recent cerebral stroke or transient ischemic attack, and (5) patients with cardiovascular or cerebrovascular diseases who were assessed by cardiac or cerebral specialists to have a "high risk" for thromboembolism for other reasons. In such group, the patients at high risk for thromboembolism who had maintained at least one antiplatelet drug, usually aspirin $100 \mathrm{mg}$, on the day before surgery were classified into the APT-HR group $(n=54)$. About $1-2$ days after confirming postoperative haemostasis, they restarted APT as soon as possible. Meanwhile, patients with low risk for thromboembolism (except both non-APT and APT-HR) in whom APT was discontinued 1 week before surgery and resumed as soon as possible after confirming haemostasis postoperative, mostly 1-2 days, were classified into the APT-LR group $(n=114)$. If patients were on long-term oral ACT, mainly warfarin, then the drug is discontinued 5 to 7 days before surgery, bridging ACT with unfractionated heparin and early postoperative reinstitution. In patients using both $\mathrm{APT}$ and oral ACT, perioperative management of APT was coupled with that of ACT.

Postoperative complications were categorised and assessed using the Clavien-Dindo classification (CDC), and CDC class II or higher was considered to have postoperative complications. Operative mortality was defined as death within 30 days postoperative. The primary outcomes included both BC and TC. The perioperative and outcome variables of the APT-HR and APT-LR groups were compared with those of the non-APT group. Univariate and multivariate analyses were used to assess the risk factors for intra- and postoperative $\mathrm{BC}$ and TC.

Data in each group were compared using chi-square or Fisher's exact probability test. Continuous variables in the patient characteristics were expressed as a median with range and compared via one-way ANOVA or Kruskal-Wallis test. Nonparametric variables were also compared using Kruskal-Wallis test with Scheffe's $F$ test. Statistical significance was set at $p<0.05$. Data were analysed using the SPSS package software (Ver. 20).

\section{Results}

A total of 168 patients (29.1\%) used APT in this cohort. The APT-HR, APT-LR, and non-APT groups included 54 (9.3\%), 114 (19.7\%), and 410 (70.9\%) patients, 


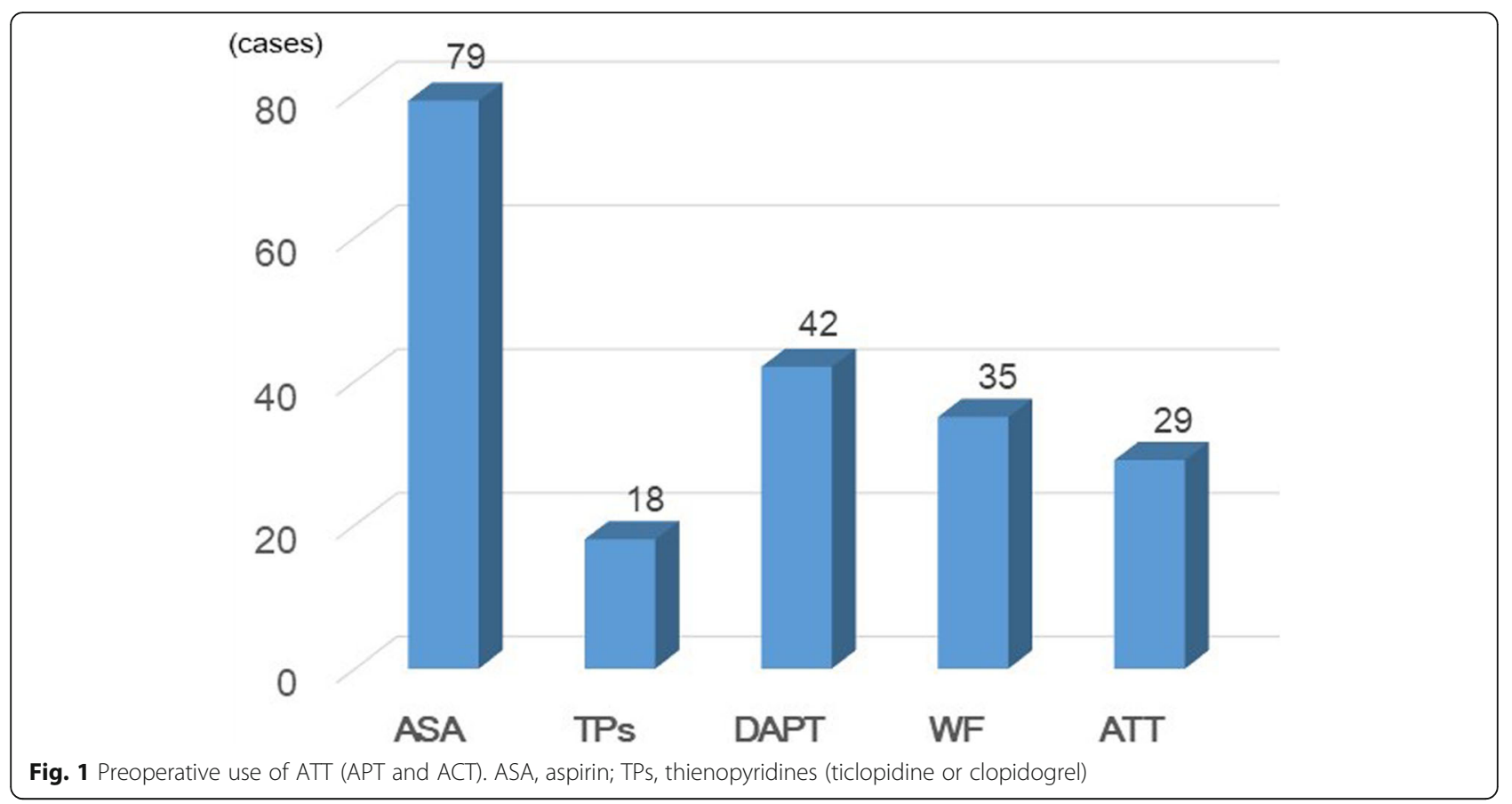

respectively. In the $\mathrm{APT}$ group, single $\mathrm{APT}$ was the most frequently used $[n=121(72 \%)]$, whereas "strong" dual APT was used in $47(28 \%)$ patients.

Table 1 shows the preoperative characteristics of patients in each group. The APT-HR and APT-LR groups had more patients with chronic heart failure, a history of coronary artery bypass grafting and $\mathrm{CI}$, poor cardiac conditions, New York Heart Association (NYHA) class II or higher heart failure, American Society of Anesthesiologists (ASA) class III or higher systemic disease, regular haemodialysis or peritoneal dialysis, and history of DM treatment. A total of 91 patients were treated via percutaneous coronary intervention (PCI), and 33 were treated via PCI with DES. The number of patients with a history of PCI and DES treatment was higher in the APT group than in the non-APT group.

Intraoperative characteristics in each group are detailed in Table 2.

No significant difference was found in operation methods $(p=0.058)$, resection in the rectum or not $(p=0.225)$. The postoperative patient characteristics and morbidity and mortality in the cohort are summarised in Table 3. Blood loss during operation $(p=0.304)$, operative time $(p=$ $0.956)$, hospitalisation after surgery $(p=0.307)$, and CDC of surgery-related complications $(p=0.467)$ were not significantly different among the three groups. No patient had uncontrollable excessive intraoperative bleeding due to continuation of APT, although the estimated amount of operative blood loss was identical between the groups.

Postoperative complications developed in $9.3 \%$ of all patients. In terms of postoperative morbidity, only seven
(1.2\%) cases of BC (six anastomotic regions and one rectal ulcer) were noted. Of these, one case each belonged to the APT-HR and APT-LR groups, and the rest were in the non-APT group. Meanwhile, four $(0.7 \%)$ cases of TC [two CI, one PTE, and one deep vein thrombosis (DVT)] and 43 cases (7.4\%) of other surgical complications were noted. Thrombus formation occurred in four patients: two CI cases in the APT-LR group and PE and DVT in the non-APT group. TC was not noted in the APT-HR group. In the APT groups, no significant differences were found in the occurrence of postoperative $\mathrm{BC}$ $(p=0.864)$ and TC $(p=0.287)$. Moreover, the occurrences of postoperative luminal bleeding $(p=0.864)$, PTE $(p=0.814)$, CI $(p=0.663)$, and DVT $(p=0.814)$ were not significantly different among the three groups. The most common complications in all the groups were superficial surgical site infection (1.6\%), anastomotic leakage (2.9\%), and small bowel obstruction (1.7\%). Among them, the incidence of small bowel obstruction was the highest in the APT-HR group $(p=0.038)$. Nevertheless, the complication rate in the APT-HR group is significantly increased $(p<0.0001)$. No operative mortality occurred in the APT-HR, APT-LR, and non-APT groups.

Detailed data on postoperative $\mathrm{BC}$ and $\mathrm{TC}$ are shown in Table 4. In terms of BC, only luminal bleeding was noted. Emergent colonoscopy was performed for postoperative haemorrhage in one APT-HR and one APT-LR cases undergoing laparoscopic anterior resection, but the bleeding was managed. Of five cases of $\mathrm{BC}$ in the non-APT group, one case of the rectal ulcer was conservative. Two 
Table 1 Preoperative characteristics of patients in the cohort

\begin{tabular}{|c|c|c|c|c|c|}
\hline Variables & Total $(n=578)$ & APT-HR $(n=54)$ & APT-LR $(n=114)$ & non-APT $(n=410)$ & p Value \\
\hline Age, y, median (range) & $70(22-96)$ & $75(50-92)$ & $76(55-96)$ & $67(22.92)$ & $<0.0001$ \\
\hline \multicolumn{6}{|l|}{$\operatorname{sex}, n(\%)$} \\
\hline Male & $348(60.2)$ & $39(72.2)$ & $84(73.7)$ & $225(54.9)$ & $<0.0001$ \\
\hline Female & $230(39.6)$ & $15(27.8)$ & $30(26.3)$ & $185(45.1)$ & \\
\hline \multicolumn{6}{|l|}{ Body mass index, $n$ (\%) } \\
\hline$<30 \mathrm{~kg} / \mathrm{m}^{2}$ & $563(97.4)$ & $52(96.3)$ & $112(98.2)$ & $399(97.3)$ & 0.743 \\
\hline$\geq 30 \mathrm{~kg} / \mathrm{m}^{2}$ & $15(2.6)$ & $2(3.7)$ & $2(1.8)$ & $11(2.7)$ & \\
\hline \multicolumn{6}{|l|}{ Perfomance status, $n(\%)$} \\
\hline 0.1 .2 & $572(99)$ & $54(100)$ & $113(99.1)$ & $405(98.8)$ & 0.696 \\
\hline 3,4 & $6(1)$ & $0(0)$ & $1(0.9)$ & $5(1.2)$ & \\
\hline \multicolumn{6}{|l|}{ ASA, $\cap(\%)$} \\
\hline $1-2$ & $413(71.5)$ & $5(9.3)$ & $48(42.1)$ & $360(87.8)$ & $<0.0001$ \\
\hline 3 more & $165(28.5)$ & $49(90.7)$ & $66(57.9)$ & $50(12.2)$ & \\
\hline \multicolumn{6}{|l|}{ NYHA2,3,4, n(\%) } \\
\hline Yes & $25(4.3)$ & $10(18.5)$ & $6(5.3)$ & $9(2.2)$ & $<0.0001$ \\
\hline No & $553(95.7)$ & $44(81.5)$ & $108(94.7)$ & $401(97.8)$ & \\
\hline \multicolumn{6}{|l|}{ CHF, n(\%) } \\
\hline Yes & $57(9.9)$ & $15(27.8)$ & $27(23.7)$ & $15(3.7)$ & $<0.0001$ \\
\hline No & $521(90.1)$ & $39(72.2)$ & $87(76.3)$ & $395(96.3)$ & \\
\hline \multicolumn{6}{|l|}{ CABG. $n(\%)$} \\
\hline Yes & $15(2.6)$ & $3(5.6)$ & $9(7.9)$ & $3(0.7)$ & $<0.0001$ \\
\hline No & $563(97.4)$ & $51(94.4)$ & $105(92.1)$ & $407(99.3)$ & \\
\hline \multicolumn{6}{|l|}{$\mathrm{PCl}$} \\
\hline Yes & $91(15.7)$ & $40(74.1)$ & $46(40.4)$ & $5(1.2)$ & $<0.0001$ \\
\hline No & $487(84.3)$ & $14(25.9)$ & $68(59.6)$ & 405 (98.8) & \\
\hline \multicolumn{6}{|l|}{ DES. $n(\%)$} \\
\hline Yes & $33(5.7)$ & $33(61.1)$ & $0(0)$ & $O(0)$ & $<0.0001$ \\
\hline No & $545(94.3)$ & $21(38.9)$ & $114(100)$ & $410(100)$ & \\
\hline \multicolumn{6}{|l|}{ History of $\mathrm{Cl}, \mathrm{n}(\%)$} \\
\hline Yes & $48(8.3)$ & $11(20.4)$ & $26(22.8)$ & $11(2.7)$ & $<0.0001$ \\
\hline No & $530(91.7)$ & $43(79.6)$ & $88(77.2)$ & $399(97.3)$ & \\
\hline \multicolumn{6}{|l|}{ HD. $n(\%)$} \\
\hline Yes & $11(1.9)$ & $4(7.4)$ & $4(3.5)$ & $3(0.7)$ & $<0.001$ \\
\hline No & $567(98.1)$ & $50(92.6)$ & $110(96.5)$ & $407(99.3)$ & \\
\hline \multicolumn{6}{|l|}{ pm, n (\%) } \\
\hline Yes & $102(17.6)$ & $19(35.2)$ & $34(29.8)$ & $49(12)$ & $<0.0001$ \\
\hline No & $476(82.4)$ & $35(64.8)$ & $80(70.2)$ & $361(88)$ & \\
\hline \multicolumn{6}{|l|}{ DAPT, $n(\%)$} \\
\hline Yes & $47(8.1)$ & $40(74.1)$ & $7(6.1)$ & $O(0)$ & $<0.0001$ \\
\hline No & $531(91.9)$ & $14(25.9)$ & 108 (93.9) & $409(100)$ & \\
\hline \multicolumn{6}{|l|}{ CAPT, $n(96)$} \\
\hline Yes & $54(9.3)$ & $54(100)$ & $0(0)$ & $O(0)$ & $<0.0001$ \\
\hline No & $524(90.7)$ & $0(0)$ & $114(100)$ & $410(100)$ & \\
\hline \multicolumn{6}{|l|}{ Anticoagulant use, $n(\%)$} \\
\hline Yes & $64(11.1)$ & $5(9.3)$ & $24(21.1)$ & $35(8.5)$ & $<0.001$ \\
\hline No & $514(88.9)$ & $49(90.7)$ & $90(78.9)$ & 375 (91.5) & \\
\hline \multicolumn{6}{|l|}{ Heparin bridging. $n(\%)$} \\
\hline Yes & $67(11.6)$ & $9(16.7)$ & $24(21.1)$ & $34(8.3)$ & $<0.0001$ \\
\hline No & $511(89.4)$ & $45(83.3)$ & $90(78.9)$ & $376(91.7)$ & \\
\hline
\end{tabular}

cases in which the rectum was anastomosed in a low degree were managed by suturing from an anal approach on the day of rectal resection under general anaesthesia. No postoperative bleeding due to resumption of APT administration was noted. In terms of TC, APT was resumed in one case that included preoperative basilar artery stenosis, but CI due to acute basilar artery occlusion developed after an operation and outside decompression procedure was performed. The patient recovered eventually. The other case that included Paf resumed ACT and APT after surgery, but arteria basilaris acute occlusion developed on the same day when APT was started. The patient was managed through absorption of the thrombus via a catheter and was saved. The PTE was accidentally discovered via preoperative CT examination, and the thrombus completely disappeared with preoperative heparin administration. During postoperative urination, she went into shock because of fresh and extensive PTE in the right main pulmonary artery; 
Table 2 Intraoperative characteristics of patients in the cohort

\begin{tabular}{|c|c|c|c|c|c|}
\hline Variables & Total $(n=578)$ & APT-HR $(n=54)$ & APT-LR $(n=114)$ & non-APT $(n=410)$ & $p$ \\
\hline \multicolumn{6}{|l|}{ Resection Type, $\mathrm{n}(\%)$} \\
\hline lleocecal & $88(15.2)$ & $10(18.5)$ & $14(12.3)$ & $64(15.6)$ & 0.058 \\
\hline Right colon & $89(15.4)$ & $10(18.5)$ & $19(16.7)$ & $60(14.6)$ & \\
\hline Transverse colon & $31(5.4)$ & $1(1.9)$ & $10(8.8)$ & $20(4.9)$ & \\
\hline Left colon & $37(6.4)$ & $1(1.9)$ & $10(8.8)$ & $26(6.3)$ & \\
\hline Sigmoid colon & $109(18.9)$ & $6(11.1)$ & $26(22.8)$ & $77(18.8)$ & \\
\hline Anterior for Rectum & $193(33.4)$ & $24(44.4)$ & $26(22.8)$ & $143(34.9)$ & \\
\hline APR for Rectum & $12(2.1)$ & $0(0)$ & $4(3.5)$ & $8(2.0)$ & \\
\hline (Sub)Total colorectum & $6(1.0)$ & $0(0)$ & $0(0)$ & $6(1.5)$ & \\
\hline Partial & $13(2.2)$ & $2(3.7)$ & $5(4.4)$ & $6(1.5)$ & \\
\hline \multicolumn{6}{|l|}{ Resection of Rectum, n (\%) } \\
\hline Yes & $135(23.4)$ & $15(27.8)$ & $20(17.5)$ & $100(24.4)$ & 0.225 \\
\hline No & $443(76.6)$ & 39 (72.2) & $94(82.5)$ & $310(75.6)$ & \\
\hline
\end{tabular}

immediately most of the thrombi were absorbed with a catheter. The other DVT case occurred after surgery, and medical treatment was provided. However, this proved inadequate because the thrombus was refractory; thus, thrombectomy was performed after insertion of an inferior vena cava filter.

We cannot conduct a multivariate analysis, because there are only seven events for BC and only four for $\mathrm{TC}$ events. It was suggested that at least cAPT does not contribute to the sharp increase in postoperative $\mathrm{BC}$ and TC.s

\section{Discussion}

Myocardial infarction (MI) is among the most important and frequent cardiovascular conditions. Although the mortality rate due to coronary heart disease has declined over the past four years, it is still responsible for one

Table 3 Postoperative characteristics and morbidity and mortality of patients in the cohort

\begin{tabular}{|c|c|c|c|c|c|}
\hline \multirow{2}{*}{$\begin{array}{l}\text { Postoperative patient characteristics } \\
\text { Variables }\end{array}$} & & & & & \\
\hline & Total $(n=578)$ & APT-HR $(n=54)$ & APT-LR $(n=114)$ & non-APT $(n=410)$ & $P$ \\
\hline Bloodloss, g, median (range) & $50.75(0-100)$ & $32.50(0-210)$ & $57.91(0-1000)$ & $51.17(0-845)$ & $P=0.304$ \\
\hline Ope time, m, median (range) & $227.9(39-823)$ & $226.7(39-512)$ & $226.2(82-519)$ & $228.5(59-823)$ & $P=0.956$ \\
\hline POD, d, median (range) & $17.2(3-143)$ & $19.0(7-143)$ & $15.8(3-63)$ & $17.4(4-132)$ & $P=0.307$ \\
\hline Cla-Din, median (range) & $0.46(0-4)$ & $0.61(0-4)$ & $0.49(0-4)$ & $0.43(0-4)$ & $P=0.467$ \\
\hline \multicolumn{6}{|l|}{ Postoperative Morbidity } \\
\hline None & 524 (91) & $41(76)$ & $104(91)$ & $379(92)$ & \\
\hline Bleeding complications & $7(1.2)$ & $1(1.9)$ & $1(0.9)$ & $5(1.2)$ & $P=0.864$ \\
\hline luminal bleeding & $7(1.2)$ & $1(1.9)$ & $1(0.9)$ & $5(1.2)$ & $P=0.864$ \\
\hline abdominal bleeding & 0 & 0 & 0 & 0 & \\
\hline abdominal wall hematoma & 0 & 0 & 0 & 0 & \\
\hline blee ding from other parts & 0 & 0 & 0 & 0 & \\
\hline Thromboembolic complications & $4(0.7)$ & $0(0)$ & $2(1.8)$ & $2(0.5)$ & $\mathrm{P}=0.287$ \\
\hline PE & $1(0.2)$ & $0(0)$ & $0(0)$ & $1(0.2)$ & $\mathrm{P}=0.814$ \\
\hline $\mathrm{Cl}$ & $2(0.3)$ & $0(0)$ & $2(1.8)$ & $0(0)$ & $P=0.663$ \\
\hline DVT & $1(0.2)$ & $0(0)$ & $0(0)$ & $1(0.2)$ & $\mathrm{P}=0.814$ \\
\hline Other surgical complications & $43(7.4)$ & $12(22)$ & $7(6.1)$ & $24(5.8)$ & \\
\hline Superficial SSI & $9(1.6)$ & $2(3.7)$ & $1(0.9)$ & $6(1.5)$ & $P=0.370$ \\
\hline Anastomotic leakage & $17(2.9)$ & $4(7.4)$ & $2(1.8)$ & $11(2.7)$ & $P=0.109$ \\
\hline Small bowel obstruction & $10(1.7)$ & $3(5.6)$ & $3(2.6)$ & $4(1)$ & $P=0.038$ \\
\hline Pnuemonia & $2(0.3)$ & $1(1.9)$ & $1(0.9)$ & $0(0)$ & $P=0.052$ \\
\hline Retro-Vaginal fistula & $1(0.2)$ & $0(0)$ & $0(0)$ & $1(0.2)$ & $P=0.814$ \\
\hline Gout attack & $2(0.3)$ & $1(1.9)$ & $0(0)$ & $1(0.2)$ & $P=0.131$ \\
\hline Withd rawing of urine & $1(0.2)$ & $0(0)$ & $0(0)$ & $1(0.2)$ & $\mathrm{P}=0.814$ \\
\hline Acute gastric dilatation & $1(0.2)$ & $1(1.9)$ & $0(0)$ & $0(0)$ & $P=0.008$ \\
\hline Total & $54(9.3)$ & $13(24)$ & $10(8.8)$ & $31(7.6)$ & $P<0.0001$ \\
\hline Postoperative Mortality & $0(0)$ & $0(0)$ & $0(0)$ & $0(0)$ & \\
\hline
\end{tabular}


Table 4 Postoperative bleeding and thromboembolic complications in the cohort

\begin{tabular}{|c|c|c|c|c|c|c|c|}
\hline & Complication & Type of APT & Pre-Treatment & Open method & When (POD) & Treatment & Outcome \\
\hline \multicolumn{8}{|l|}{ Bleeding complications } \\
\hline & Anasto & HR & APT & LAR & 7 & CS; Observe & Good \\
\hline & Anasto & LR & APT & HAR & 1 & CS; Clip+Trombin & Good \\
\hline & Ulcer & non & - & LAR & 7 & Obser & Good \\
\hline & Anasto & non & - & Super-LAR & 0 & Suturing & Good \\
\hline & Anasto & non & - & LAR & 0 & Suturing & Good \\
\hline & Anasto & non & - & Rt.Hemi & 0 & CS; Clip+Trombin & Good \\
\hline & Anasto & non & - & Rt.Hemi & 3 & CS; Clip+Trombin & Good \\
\hline \multicolumn{8}{|l|}{ Thromboembolic complications } \\
\hline & $\mathrm{Cl}$ & LR & APT & LAR & 12 & Outside decompression & Good \\
\hline & $\mathrm{Cl}$ & LR & ATT & $\mathrm{s}$ & 3 & Thrombus aspiration & Good \\
\hline & $\mathrm{PE}$ & non & ACT & $T$ & 4 & Thrombus aspiration & Good \\
\hline & DVT & non & - & RtHemi & 8 & Thrombectomy & Good \\
\hline
\end{tabular}

third of all deaths for men aged 35 years and older in Europe [1] and one fifth of all deaths in the USA in 2014 [2]. Along with MI, stroke is a major healthcare problem causing $\sim 10 \%$ of deaths worldwide [3] and is the leading cause of disability, with $20 \%$ of survivors requiring institutional care after 3 months and $15-30 \%$ being permanently disabled [4]. Aspirin is beneficial during acute MI and acute ischemic stroke $[5,6]$ and is effective in the secondary prevention of future cardiovascular events [7]. Aspirin may be proper to survival by attenuating the severity of recurrent thrombosis-mediated events rather than reducing the occurrence of MI [8]. Continuation of aspirin may still be reasonable in patients with high-risk coronary artery disease or cerebrovascular disease, where the risks of potential increased cardiovascular events outweigh the risks of increased bleeding [9].

As the number of patients with cardiovascular disease increases in the ageing population, antiplatelets have become among the most frequently prescribed drugs. An increasing percentage of patients referred for surgical treatment have consumed long-term APT, which significantly increases the risk of peri- and postoperative $\mathrm{BC}[10]$; thus, APT is often discontinued during the preoperative period. However, discontinuing APT may increase the risk of TC. Once TC has occurred, the possibility that it will be more severe than $\mathrm{BC}$ is high. Hence, the perioperative management protocol for patients receiving APT includes, at least, a single antiplatelet agent (usually aspirin) maintained preoperatively in patients with high thromboembolic risk. Thus, if the risk of $\mathrm{BC}$ does not increase with continued APT, proactively continuing APT to prevent $\mathrm{TC}$ is reasonable. It is recommended to continue aspirin perioperatively if the bleeding risk allows, and to resume the recommended antiplatelet therapy as soon as possible postoperatively [11]. Recently, a meta-analysis reported that APT during non-cardiac surgery confers minimal bleeding risk with no difference in thrombotic complications [12]. Such a finding has been discussed in the management of perioperative antiplatelet agents, but the conclusions lack evidence. Therefore, balancing the bleeding risks after continuation of APT and thromboembolic risks after cessation of APT during the perioperative period is based on the surgeon's prerogative.

The paradigm in colorectal and general surgery has shifted over the past decade toward increasing the role of minimally invasive approaches. Laparoscopic colon resection was initially described by both Jacobs et al. and Fowler et al. in 1991 [13, 14]. Given that an increasing number of colorectal surgeons use these approaches regularly, laparoscopic colorectal surgery has been established as a safe and superior technique in many general surgery procedures. A Japanese randomised controlled trial reported that laparoscopic D3 surgery was similar to open D3 surgery in terms of overall survival for patients with stage II or III colon cancer. Moreover, laparoscopic D3 surgery can be a treatment option for patients with stage II or III colon cancer [15].

The higher the number of laparoscopic surgeries for colorectal cancer, the higher the number of patients with severe complications, such as cardiovascular or cerebrovascular disorders. For patients with high risk of ischemia due to ACS presentation or complicated coronary revascularisation procedure, postponing surgery up to 6 months after ACS or PCI may be reasonable as an additional means of protection to minimise the risk of preoperative $\mathrm{MI}$, and based on unmatched retrospective registry data if the risks of further delaying surgery are acceptable. However, in patients undergoing non-cardiac surgery after recent ACS or stent implantation, the benefits of early surgery for certain malignant tumours should be balanced against the risk of cardiovascular events. Many patients with these complications are taking $\mathrm{APT}$, and discussion on various effects of APT on laparoscopic colorectal resection is inevitable. The risk of thromboembolism in laparoscopic colorectal surgery was previously reported to increase due to an increase in intraperitoneal pressure caused by pneumoperitoneum 
[16]. However, the incidence of venous thromboembolism was lower in laparoscopic colorectal surgery than in open surgery $[17,18]$, and our findings indicate a considerably low rate. We also examined $\mathrm{BC}$ and $\mathrm{TC}$ in terms of APT use in patients who underwent standardised laparoscopic colorectal resection for colorectal cancer in our department.

In general, the patients subjected to laparoscopic surgery had lesser blood loss, longer operation time, shorter hospital stay, and lower morbidity than those who underwent open surgery [19]. In this study, postoperative morbidity rates $(9.3 \%)$ for patients with severe complications were also low. In terms of APT, the rate of complications, including BC and TC, was significantly higher in the APT-HR group, but no significant difference was noted among the three groups in terms of both BC and TC. The APT-HR group has been treated for cardiovascular diseases and with concentrated antiplatelet therapy compared to other groups (Table 1), which causes higher complications as suggested. Aside from the two cases of bleeding from a close anastomotic region in the rectum, hospital stay was not prolonged. Bleeding due to continuation of APT was not noted in any patient. All bleeding episodes were successfully managed without an increase in bleeding-related mortality. Moreover, all the four TC cases were not in the APTHR group. Although the incidence of TC was fewer compared with that of $\mathrm{BC}$, catheterisation was done in two patients, and others were subjected to invasive operation. All patients were managed successfully, but the likelihood of fatal complications, particularly TC, was high. Using perioperative aggressive APT (continuation of single APT up to the day before surgery; cAPT) was not an important factor for both $\mathrm{BC}$ and $\mathrm{TC}$. If $\mathrm{BC}$ does not increase with cAPT, then this protocol seems to be useful for suppressing fatal $\mathrm{TC}$, even in general surgery such as laparoscopic colorectal surgery.

We showed that our perioperative antiplatelet management is safe and effective as evidenced by a low TC and BC rate and that advanced laparoscopic colorectal resection can achieve satisfactory results even under continuation of single APT. As such, using cAPT (usually aspirin) can be recommended for almost all patients with thromboembolic risk who will undergo minimally invasive procedures, such as laparoscopic surgery. This retrospective analysis aimed to evaluate the safety of antiplatelet agents in the perioperative management of patients undergoing general laparoscopic colorectal resection for colorectal cancer. For the optimal management of perioperative APT for various types of diseases and surgical procedures, collecting and analysing more cases are necessary in future studies.

\section{Conclusions}

Based on the results of analysis of more than 500 cases of laparoscopic colorectal resection for colorectal cancer,
APT was not a substantial factor for fatal $\mathrm{BC}$ and TC. In patients with high thromboembolic risk, continuing aspirin inhibited the increase of TC without increasing BC during the perioperative period. For patients with high thromboembolic risk who will be subjected to minimally invasive procedures, such as laparoscopic surgery, a more aggressive management during the perioperative period using aspirin monotherapy should be considered.

\section{Acknowledgements}

The authors thank all the staff of our hospital involved in surgery and patient management

\section{Author's contributions}

TF helped with the study concept and design, analysis, and interpretation of the patient data and was a major contributor in writing the manuscript. TF, AT, YY, HH, NS, CN, and TY contributed to the data acquisition. TF and AT helped with the critical revision. All authors read and approved the final manuscript.

\section{Funding}

This research did not receive any specific grant from funding agencies in the public, commercial, or not-for-profit sectors.

\section{Availability of data and materials}

The datasets used and analysed during the current study are available from the corresponding author on reasonable request.

\section{Ethics approval and consent to participate}

The investigations were performed in compliance with the principles of good clinical practice outlined in the Declaration of Helsinki and federal guidelines. This study was approved by the local ethic committee, and written informed consent was obtained from every participant or the participant's guardian.

\section{Consent for publication}

Consent for publication was obtained from every individual whose data are included in this manuscript.

\section{Competing interests}

The authors declare that they have no competing interests.

Received: 15 April 2019 Accepted: 22 May 2019

Published online: 01 June 2019

\section{References}

1. Lloyd-Jones D, Adams R, Carnethon M, De Simone G, Ferguson TB, Flegal K, et al. Heart disease and stroke statistics--2009 update: a report from the American Heart Association Statistics Committee and Stroke Statistics Subcommittee. Circulation. 2009;119:480-6.

2. Bavry AA, Elgendy IY, Elbez Y, Mahmoud AN, Sorbets E, Steg PG, Bhatt DL. Aspirin and the risk of cardiovascular events in atherosclerosis patients with and without prior ischemic events. Clin Cardiol. 2017;40:732-9.

3. Chen ZM, Jiang LX, Chen YP, Xie JX, Pan HC, Peto R, et al. Addition of clopidogrel to aspirin in 45,852 patients with acute myocardial infarction: randomised placebo-controlled trial. Lancet. 2005;366:1607-21.

4. Sabatine MS, Cannon CP, Gibson CM, López-Sendón JL, Montalescot G, Theroux $\mathrm{P}$, et al. Addition of clopidogrel to aspirin and fibrinolytic therapy for myocardial infarction with ST-segment elevation. N Engl J Med. 2005; 352:1179-89.

5. International Stroke Trial Collaborative Group. The International Stroke Trial (IST): a randomised trial of aspirin, sub-cutaneous heparin, both, or neither among 19435 patients with acute ischaemic stroke. Lancet. 1997;349:1569-81.

6. Collaborative meta-analysis of randomised trials of antiplatelet therapy for prevention of death, myocardial infarction, and stroke in high risk patients. Antithrombotic Trialists' Collaboration BMJ. 2002;324:71-86.

7. Nichols M, Townsend N, Scarborough P, Rayner M. Cardiovascular disease in Europe 2014: epidemiological update. Eur Heart J. 2014;35:2950-2959.

8. Murray CJ, Lopez AD. Global mortality, disability, and the contribution of risk factors: Global Burden of Disease Study. Lancet. 1997;349:1436-42. 
9. Goldstein LB, Bushnell CD, Adams RJ, Appel LJ, Braun LT, Chaturvedi S, et al. Guidelines for the primary prevention of stroke: a quideline for healthcare professionals from the American Heart Association/American Stroke Association. Stroke. 2011:42:517-84.

10. Columbo JA, Lambour AJ, Sundling RA, Chauhan NB, Bessen SY, Linshaw $\mathrm{DL}$, et al. A meta-analysis of the impact of aspirin, clopidogrel, and dual antiplatelet therapy on bleeding complications in noncardiac surgery. Ann Surg. 2018;267:1-10.

11. Bhatt DL, Fox KA, Hacke W, et al. Clopidogrel and aspirin versus aspirin alone for the prevention of atherothrombotic events. N Engl J Med. 2006;354:1706-17.

12. ISIS-2 (Second International Study of Infarct Survival) Collaborative Group. Randomised trial of intravenous streptokinase, oral aspirin, both, or neither among 17,187 cases of suspected acute myocardial infarction: ISIS-2. Lancet. 1988;2:349-360.

13. R S, Vogel JD, Kiran RP. Risk of postoperative venous thromboembolism after laparoscopic and open colorectal surgery: an additional benefit of the minimally invasive approach? Dis Colon Rectum. 2011;54:1496-502.

14. Fujikawa T, Tanaka A, Abe T, Yoshimoto Y, Tada S, Maekawa H, Shimoike N. Does antiplatelet therapy affect outcomes of patients receiving abdominal laparoscopic surgery? Lessons from more than 1,000 laparoscopic operations in a single tertiary referral hospital. J Am Coll Surg. 2013;217:1044-53.

15. Fujikawa T, Tanaka A, Abe T, Yoshimoto Y, Tada S, Maekawa H. Effect of antiplatelet therapy on patients undergoing gastroenterological surgery: thromboembolic risks versus bleeding risks during its perioperative withdrawal. World J Surg. 2015;39:139-49.

16. Yamamoto S, Inomata M, Katayama H, Mizusawa J, Etoh T, Konishi F, et al. Short-term surgical outcomes from a randomised controlled trial to evaluate laparoscopic and open D3 dissection for stage II/III colon cancer: Japan Clinical Oncology Group Study JCOG 0404. Ann Surg. 2014;260:23-30.

17. Grines CL, Bonow RO, Casey DE Jr, Gardner TJ, Lockhart PB, Moliterno DJ, et al. Prevention of premature discontinuation of dual antiplatelet therapy in patients with coronary artery stents: a science advisory from the American Heart Association, American College of Cardiology, Society for Cardiovascular Angiography and Interventions, American College of Surgeons, and American Dental Association, with representation from the American College of Physicians. Circulation. 2007;115:813-8.

18. Korte W, Cattaneo M, Chassot PG, Eichinger S, von Heymann C, Hofmann N, et al. Peri-operative management of antiplatelet therapy in patients with coronary artery disease: joint position paper by members of the working group on Perioperative Haemostasis of the Society on Thrombosis and Haemostasis Research (GTH), the working group on Perioperative Coagulation of the Austrian Society for Anesthesiology, Resuscitation and Intensive Care (ÖGARI) and the Working Group Thrombosis of the European Society for Cardiology (ESC). Thromb Haemost. 2011;105:743-9.

19. Mita K, Ito H, Murabayashi R, Sueyoshi K, Asakawa H, Nabetani M, et al. Postoperative bleeding complications after gastric cancer surgery in patients receiving anticoagulation and/or antiplatelet agents. Ann Surg Oncol. 2012:19:3745-52.

\section{Publisher's Note}

Springer Nature remains neutral with regard to jurisdictional claims in published maps and institutional affiliations.

Ready to submit your research? Choose BMC and benefit from:
- fast, convenient online submission
- thorough peer review by experienced researchers in your field
- rapid publication on acceptance
- support for research data, including large and complex data types
- gold Open Access which fosters wider collaboration and increased citations
- maximum visibility for your research: over 100M website views per year
At BMC, research is always in progress.
Learn more biomedcentral.com/submissions

